\title{
Observations on the electron-dense bodies of the PKX parasite, agent of proliferative kidney disease in salmonids
}

\author{
D. J. Morris*, A. Adams, R. H. Richards \\ Institute of Aquaculture, University of Stirling, Stirling, Scotland FK9 4LA, UK
}

\begin{abstract}
Ultrastructural observations on structures associated with the 'haplosporosome'-like electron-dense bodies (EDBs) of the primary cell of the extrasporogonic stage of PKX are described. Observations made include formation of EDBs by the trans-Golgi network, an additional membrane associated with EDB structure, confronting cisternae, engulfment and presence of EDBs in multivesicular bodies, fusion of EDBs with the plasmalemma, degeneration of EDBs in disintegrating primary cells and endocytosis of PKX cytoplasm by adherent macrophages. Immunogold localisation of a PKXspecific monoclonal antibody (MAb A3) suggests that the EDBs contain periodate-sensitive carbohydrates on their membranes. Tissues prepared for immunogold electron microscopy further suggest that some contain a lipid-rich core. An interpretation is made on their possible function and their relationship with the haplosporosomes and sporoplasmasomes found in members of the Haplosporidea and Myxosporea respectively.
\end{abstract}

KEY WORDS: PKD · Myxosporea · Ultrastructure $\cdot$ Haplosporosomes $\cdot$ Sporoplasmasomes

\section{INTRODUCTION}

Proliferative kidney disease (PKD) is a commercially important disease affecting salmonid culture in Western Europe and North America (Hedrick et al. 1993). The disease is seasonal, occurring during the summer months, and is characterised by a chronic inflammation of the kidney. The organism that causes the disease is a myxosporean parasite of uncertain classification, referred to as PKX. This parasite has 2 known developmental phases in the kidney, the extrasporogonic and sporogonic stages. The extrasporogonic stage proliferates in the kidney interstitium and is composed of a primary cell containing 1 or more secondary cells within it. These secondary cells, released by the primary cell, form sporogonic stages in the kidney tubule lumens (Kent \& Hedrick 1986).

The typical ultrastructural characteristics of PKX have been documented (Ferguson \& Needham 1978,

•E-mail: djm4@stir.ac.uk
Seagrave et al. 1980, Feist \& Bucke 1987, MacConnell et al. 1989). The primary cell of the extrasporogonic parasite has an electron-dense plasmalemma, mitochondria, rough and smooth endoplasmic reticulum (ER), lysosomes and residual bodies. The primary cell is characterised by distinctive 'electron-dense bodies' (EDBs), whose function remains unknown. The bodies are membrane-bound spheroids 130 to $200 \mathrm{~nm}$ in diameter. They have an electron-lucent bar that extends roughly halfway into them which can be lined by a folding of the bodies' delimiting membrane. The bodies are often associated with the plasmalemma, to which the electron-lucent bar is orientated at an angle of $90^{\circ}$ (Ferguson \& Needham 1978, Seagrave et al. 1980). Similarities were noted between the EDBs of PKX and the haplosporosomes contained within some members of the Haplosporidea. This led to the hypothesis that PKX was a haplosporidean parasite although other ultrastructural features indicated similarities with the Myxosporea (Seagrave et al. 1980). With the description of sporogonic forms, PKX was classed as a 
myxosporean (Kent \& Hedrick 1986). Subsequent phylogenetic analysis has demonstrated that PKX is a member of a sister taxon to the Myxosporea (Kent et al. 1998, Saulnier et al. 1999), Many myxosporeans possess dense bodies in the cytoplasm of their sporoplasms. These were termed sporoplasmasomes to distinguish them from the haplosporosomes of the Haplosporidea (Lom et al. 1986). However, the EDBs of PKX appear to be morphologically distinct from the sporoplasmasomes of most other myxosporeans. Two other parasites have been identified that possess similar EDBs to PKX, the myxosporean Tetracapsula bryozoides and an unclassified intracellular parasite of carp (Voronin \& Chernysheva 1993, Canning et al. 1996).

The present paper describes aspects of EDB morphology, biochemical composition and structures associated with EDBs in PKX. From these observations, an interpretation is made of their structure, development and possible function.

\section{MATERIALS AND METHODS}

Electron microscopy. PKX-infected kidney was removed from moribund fingerling rainbow trout $O n$ corhynchus mykiss and cut into $0.5 \mathrm{~mm}^{3}$ cubes. These were fixed in Karnovskys fixative for $4 \mathrm{~h}$ and rinsed in cacodylate buffer ( $\mathrm{pH}$ 7.2) overnight. They were then post fixed in $1 \%$ osmium tetroxide, dehydrated through an acetone to alcohol series and embedded in araldite. Ultrathin gold sections were mounted on formvar coated grids and stained with lead citrate and uranyl acetate. The sections were viewed at $80 \mathrm{kV}$ using a Phillips 201 electron microscope.

Immunogold electron microscopy. Infected kidney tissue was also processed for immunogold electron microscopy following the method of Morris et al. (1997). Briefly, the kidney was cut into $0.5 \mathrm{~mm}^{3}$ cubes and fixed overnight at $4^{\circ} \mathrm{C}$ in $5 \%$ gluteraldehyde in PIPES buffer (200 mM N'N'bis[2-ethanesulphonic acid] $\mathrm{pH}$ 5.5). The tissue was then rinsed in PIPES buffer 3 times followed by 2 rinses in distilled water. The tissue was dehydrated through a graded alcohol series to $70 \%$ alcohol and embedded in LR white (London Resin Co., Reading, UK). Ultrathin sections were cut and mounted on nickel grids. Non-specific binding sites on the sections were blocked by floating the grids section- side down on $10 \%$ foetal calf serum in wash buffer (0.2 M Tris buffered saline, 1\% Tween, $1 \%$ bovine serum albumin, $\mathrm{pH}$ 7.5) overnight. The grids were transferred to drops of the monoclonal antibody A3 (MAb A3) hybridoma supernatant and again incubated overnight. MAb A3 was developed by Morris et al. (1997) and appears to recognise a periodate-sensitive carbohydrate antigen present on the lysosomal membranes and plasmalemma of the primary PKX cell. After washing in wash buffer, the grids were incubated on drops of $10 \mathrm{~nm}$ gold colloid conjugated to sheep anti-mouse antibody (Sigma) diluted 1:40 in wash buffer. The grids were then washed in wash buffer followed by distilled water. The sections were counterstained in lead citrate/uranyl acetate. All of the sections were viewed under a Phillips 201 electron microscope at $80 \mathrm{kV}$.

\section{RESULTS}

The ultrastructure of the PKX extrasporogonic parasite revealed features of the parasite already described in the literature such as residual bodies, smooth and rough ER, nucleus, secondary lysosomes, Golgi apparatus, and cristate mitochondria. The organelles were typically situated throughout the cytoplasm except directly under the plasmalemma. There, the cytoplasm usually only contained EDBs. Secondary cells, when present, were delimited from the primary cell by a double plasma membrane (Fig. 1). One extrasporogonic PKX parasite was observed with a distinct polarity in the location of the organelles in its cytoplasm. Here, the organelles, including the secondary cell, were clustered at one end of the cell. The rest of this parasite consisted of cytoplasm and sparse ER with clusters of EDBs located beneath the plasmalemma. Different stages of the parasites development were observed in the same tissue section. These stages included interstitial extrasporogonic parasites containing 1 or $2 \mathrm{sec}-$ ondary cells, disintegrating primary cells releasing secondary cells, intratubular extrasporogonic PKX and intratubular sporogonic stages. Observations were made on 3 types of structure in the primary cell of PKX. These structures were the EDBs, structures associated with the EDBs and ultrastructural observations on the primary cells' plasmalemma and associated macrophages.

Figs. 1 to 6. PKX extrasporogonic parasite. Fig. 1. Typical extrasporogonic PKX. ( $\star$ ) Secondary cell. Scale bar $=1$ mm. Fig. 2. EDB with 'tail'. Scale bar $=130 \mathrm{~nm}$. Fig. 3. EDBs aligned to plasmalemma. Arrowhead: membrane capping the lucent bar of body. Scale bar $=100 \mathrm{~nm}$. Fig. 4. Immunolocalisation of MAb A3 on EDBs as well as plasmalemma and lysosomal membrane. Scale bar $=150 \mathrm{~nm}$. Fig. 5. Electron-lucent ' $T$ ' in EDB. Scale bar $=130 \mathrm{~nm}$. Fig. 6. EDB with 4 electron-lucent areas around lucent core (arrowhead). Scale bar $=100 \mathrm{~nm}$ 


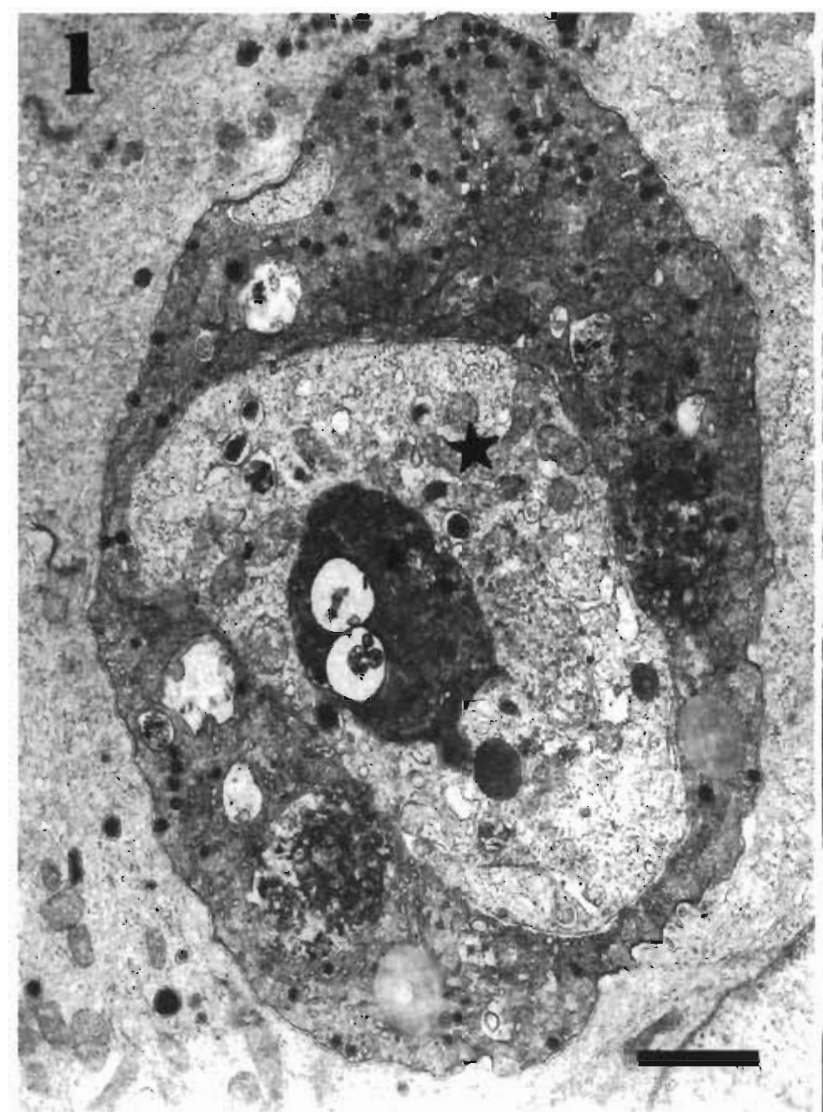

\section{6 ras}

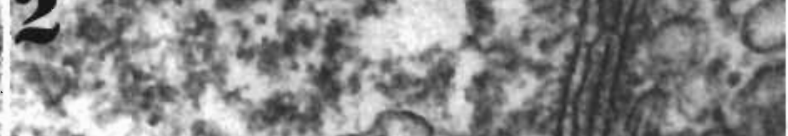

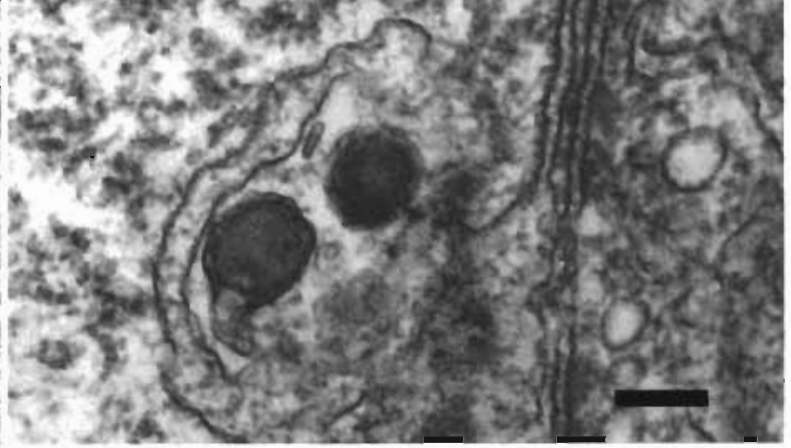

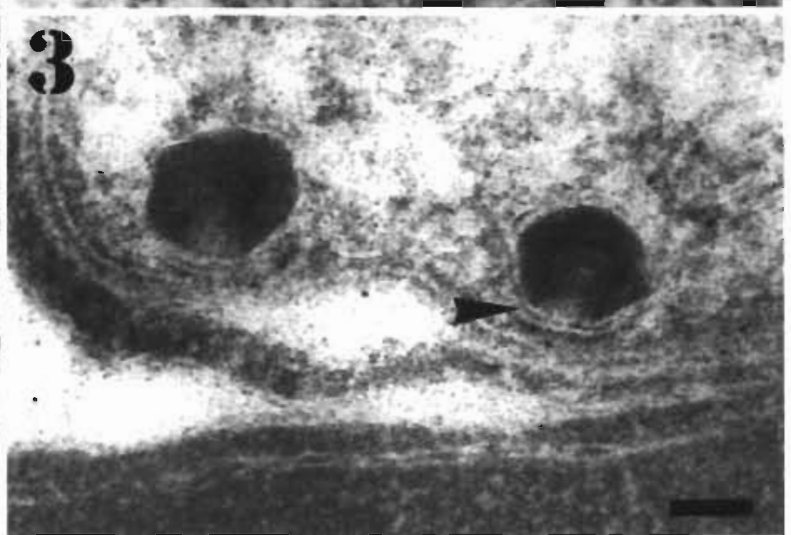

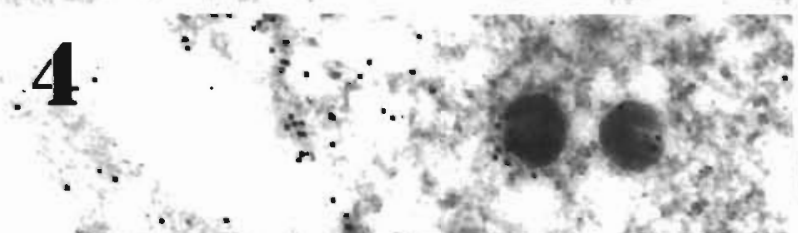

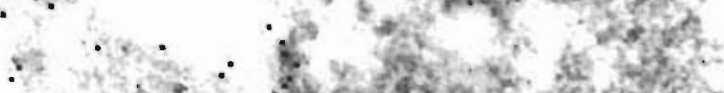

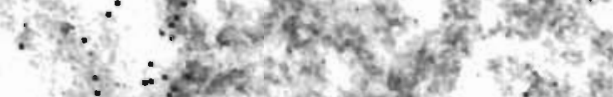

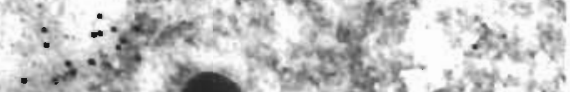

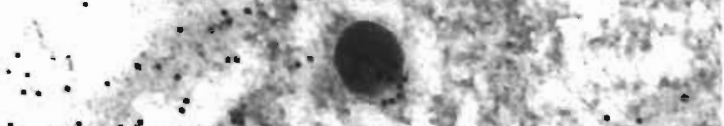

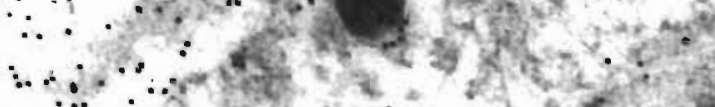

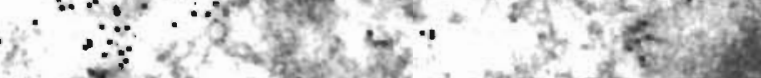

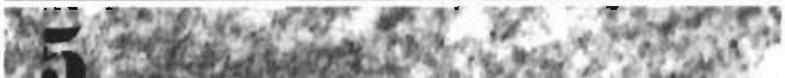

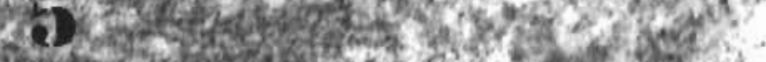

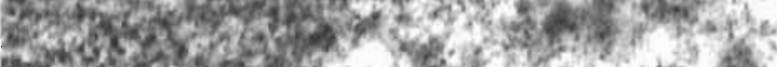

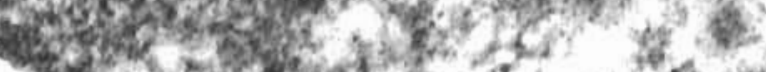

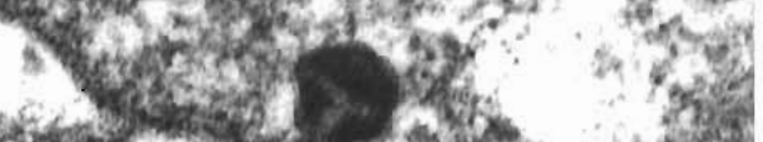

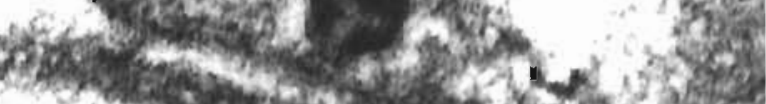

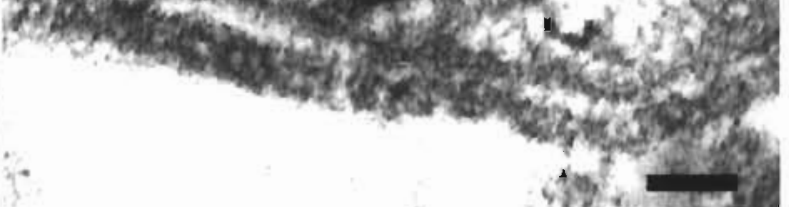

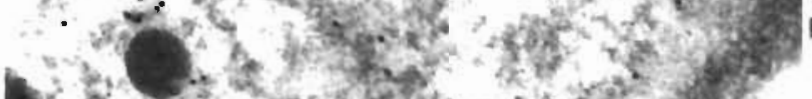

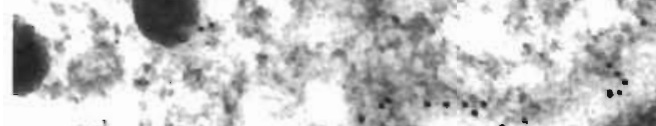

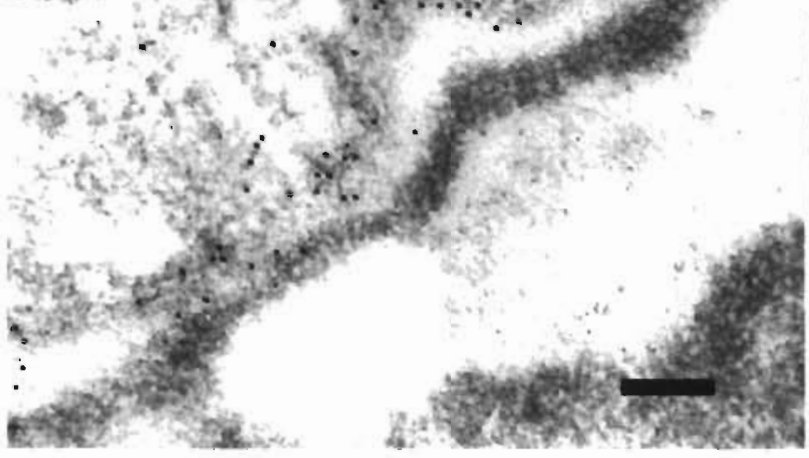

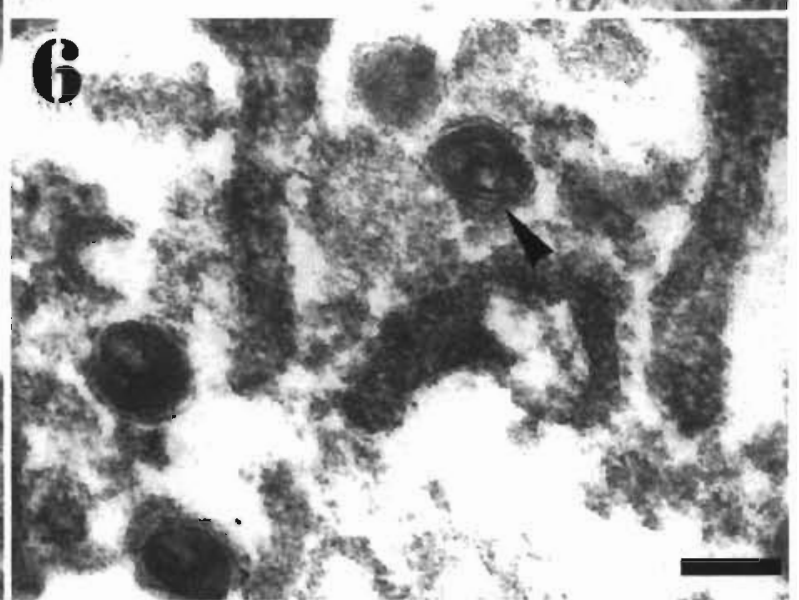




\section{Electron-dense bodies}

EDBs were noted throughout the cytoplasm of the primary cell of the extrasporogonic parasite. Occasional EDBs were noted in endocytotic vacuoles contained in secondary cells. Tertiary cells, when present, were never seen to contain EDBs. The majority of the EDBs examined resembled those described in the literature as 130 to to $160 \mathrm{~nm}$ in diameter, possessing a membrane-bound dense matrix with an electronlucent bar extending $1 / 2$ to $3 / 4$ of the way into them. EDBs were also noted orientated towards the plane of section. These had the appearance of a membranebound electron-dense disk with a membrane-bound electron-lucent centre. EDBs with membrane tails were occasionally noted in the cytoplasm of the primary cell of the parasite as described by Ferguson \& Needham (1978). The length of these 'tails' was variable, ranging from 90 to $400 \mathrm{~nm}$ in length (Fig. 2). On some EDBs where the bodies encapsulating membrane was continuous with the membrane lining the lucent bar there was a separate, distinct membrane that capped the bar (Fig. 3). For EDBs where the encapsulating membrane did not line the lucent bar but delimited the whole of the body this capping membrane was not discernible. Immunogold studies demonstrated that $\mathrm{MAB} A 3$ bound to an antigen associated with the capping membrane as well as antigen on the encapsulating membrane of the EDBs (Fig. 4). In sections prepared for immunogold electron microscopy some EDBs were noted that contained an electron-lucent ' $\mathrm{T}$ ' rather than a lucent bar (Fig. 5). In these tissue sections, cross-sections through some of the EDBs orientated towards the plane of section revealed that the electron-lucent centre had 4, additional lucent areas surrounding it. These areas appeared to be membrane lined and were arranged at $90^{\circ}$ intervals around the central lucent area (Fig. 6). A disintegrating primary cell containing an intact secondary cell was observed releasing large numbers of EDBs and EDBlike vesicles into the kidney interstitium. Due to the disintegration of the primary cell, these EDB-like vesicles were identified as degenerating EDBs. They were spherical, 100 to $200 \mathrm{~nm}$ in diameter, and possessed an electron-lucent crescent to one side of a dense matrix
(Fig. 7). The cytoplasm of this primary cell was much reduced, appearing to contain few organelles or matrix.

\section{Plasmalemma and associated macrophages}

Areas of the extrasporogonic parasite's plasmalemma appeared to be very electron dense while some areas possessed a less distinct membrane (Fig. 8). Some areas of the macrophage plasmalemma that were in close proximity with the parasite also appeared electron dense. Often the PKX in the kidney interstitium appeared to be totally engulfed by 1 or 2 macrophages. The parasite and macrophage's plasmalemmas sometimes became interdigitated with each other, the membranes being separated by an intracellular space occupied by the cells' glycocalyx (Fig. 9). In contrast, the extrasporogonic and sporogonic PKX stages present in the kidney tubule lumens were never observed associated with macrophages. The EDBs were often aligned to the plasmalemma of the parasite with their electron-lucent bars aligned at $90^{\circ}$ to the surface of the parasite. Most of the EDBs were positioned $20 \mathrm{~nm}$ below the surface of the plasmalemma although some appeared to be in direct contact with it. Occasionally, the membrane of an electron-lucent bar appeared to interact with or directly fuse with the plasmalemma (Figs. $9 \& 10$ ). When the membranes fused, the EDBs membrane appeared to contribute to areas of dense plasmalemma. Occasionally, the adherent macrophages appeared to be in the process of endocytosing portions of the primary cell cytoplasm. Vacuoles containing EDBs were observed in the adhering macrophages although it could not be ascertained whether these represented truly endocytosed material or were an effect of plane of section. One macrophage appeared to be in the process of endocytosing a quantity of cytoplasm from a PKX primary cell that contained membrane-bound ovoid particles. These particles were variable in size from 20 to $60 \mathrm{~nm}$ in diameter (Fig. 11). This cytoplasmic structure resembled an unidentified surface projection described previously in Bonamia sp. by Hine \& Wesney (1992). EDBs appeared to be released from the primary cell into the intracellular space in areas where the par-

Figs. 7 to 11 PKX extrasporogonic parasite. Fig. 7. Disintegration of primary cell of extrasporogonic PKX containing large numbers of membrane-bound inclusions. ( $\star$ ) Secondary cell. Scale bar $=300 \mathrm{~nm}$. Fig. 8 . Areas of electron-dense plasmalemma of PKX primary cell. Arrowheads: corresponding electron-dense areas of host cell. ( $\star$ Host cell. Scale bar $=300 \mathrm{~nm}$. Fig. 9 . Interdigitating of primary cell of extrasporogonic PKX with macrophage ( $\star$ ). Scale bar $=160 \mathrm{~nm}$. Insert: magnified area of EDB in Fig. 10 showing interaction between the EDB's membrane and the plasmalemma (arrowhead). Scale bar $=100 \mathrm{~nm}$. Fig. 10. Macrophage appearing to endocytose part of primary cell ( $\star$ ). Arrowhead: electron-dense body fusing with cell surface Scale bar $=200 \mathrm{~nm}$. Fig. 11. Surface projection on extrasporogonic parasite. $(\star)$ Host cell. Scale bar $=140 \mathrm{~nm}$ 


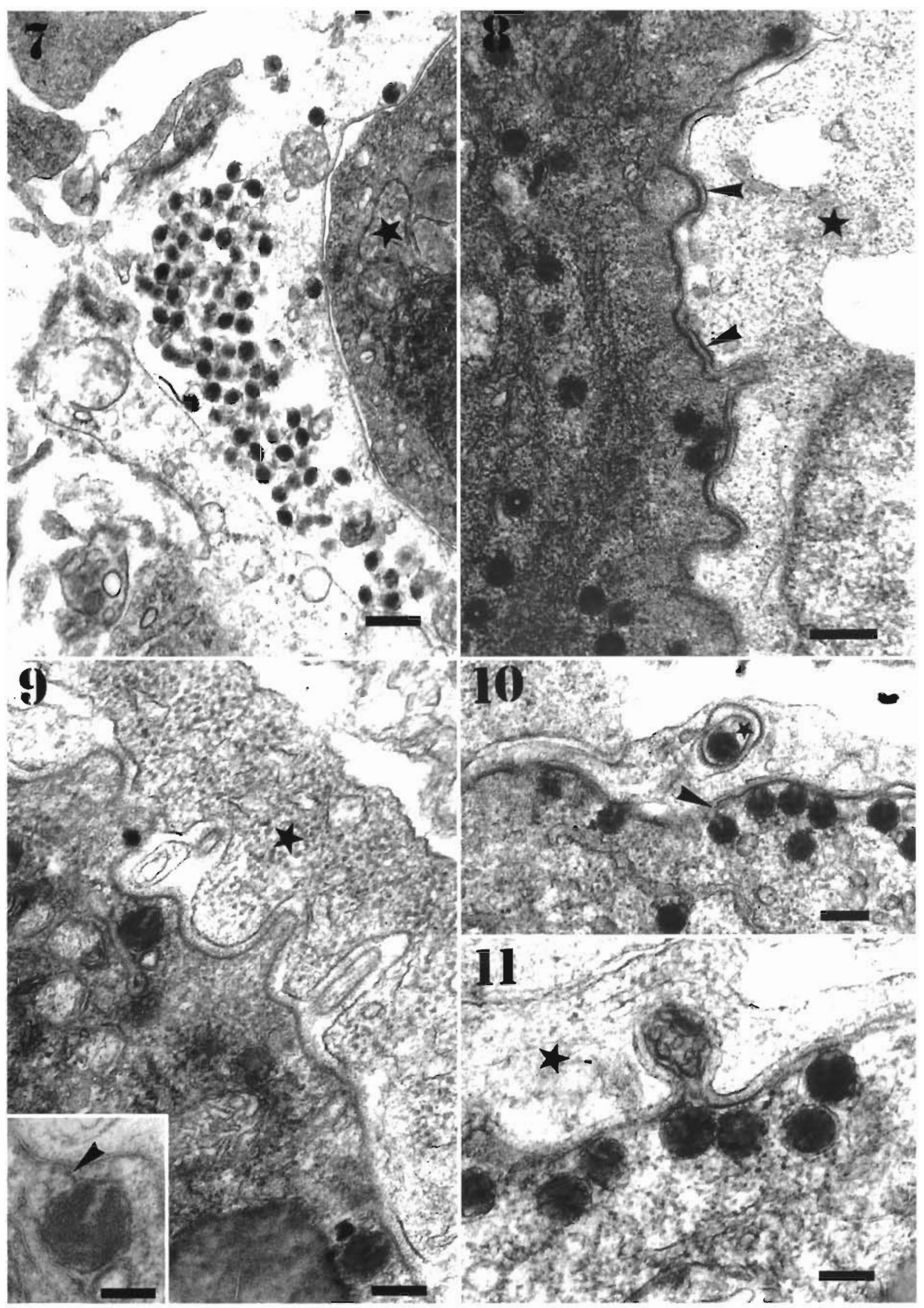


asites' plasmalemma could not be easily discerned (Fig. 12). However, expulsion of either whole EDBs or EDB contents extracellularly from areas with a distinct plasmalemma was never observed in this study.

\section{Structures associated with the EDBs}

Genesis of EDBs was noted on the trans-Golgi face of the Golgi apparatus. EDBs were actively engulfed by cup-like structures resembling multivesicular bodies (MVBs) and their presence within developing MVBs was noted (Fig. 13). Some EDBs appeared to be aligned to the surface of vesicular structures within the primary cell cytoplasm. However, it could not be determined whether these were truly internal structures or an effect due to the plane of section cutting through an interdigitated macrophage. In one section, 7 EDBs were observed with their electron-lucent bars aligned $90^{\circ}$ towards confronting cisternae (Fig. 14). These cis-

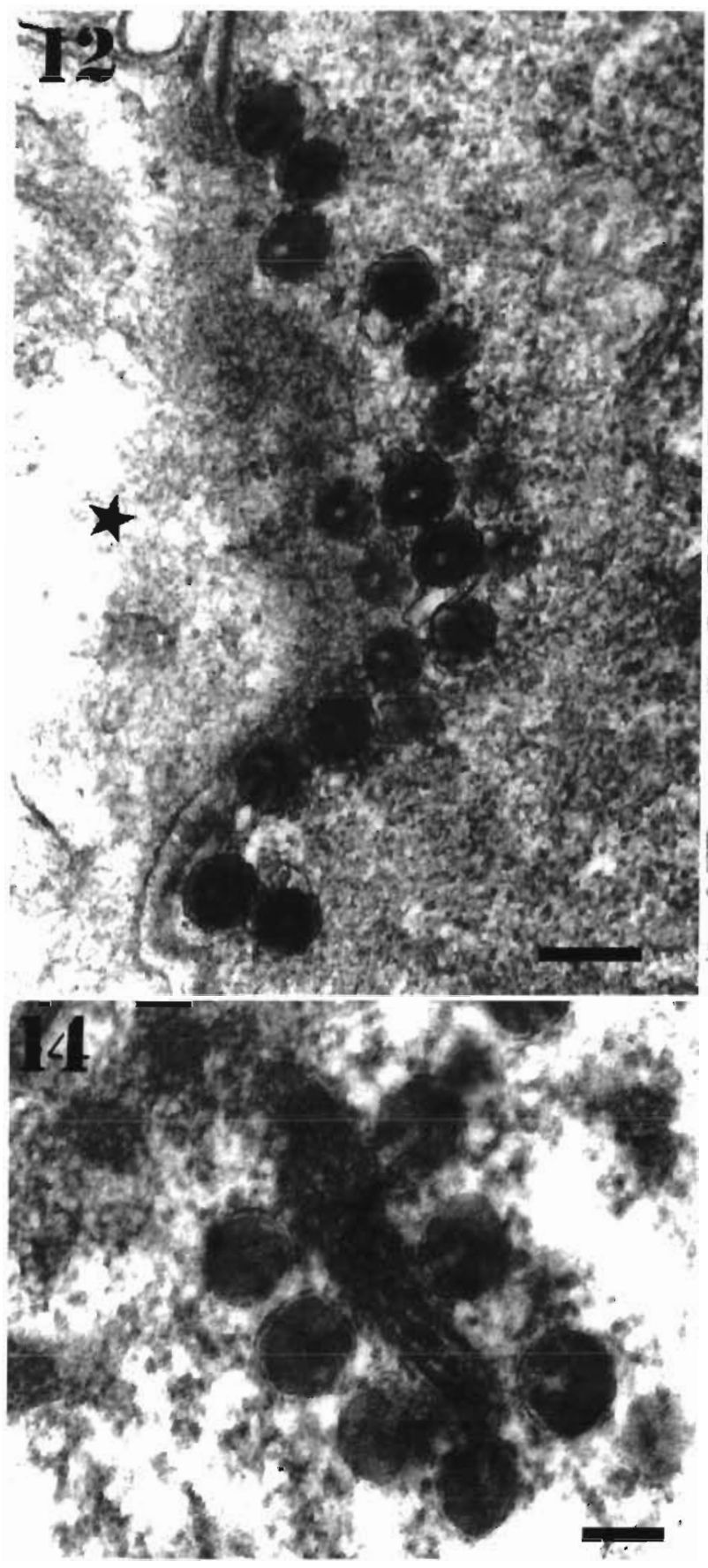

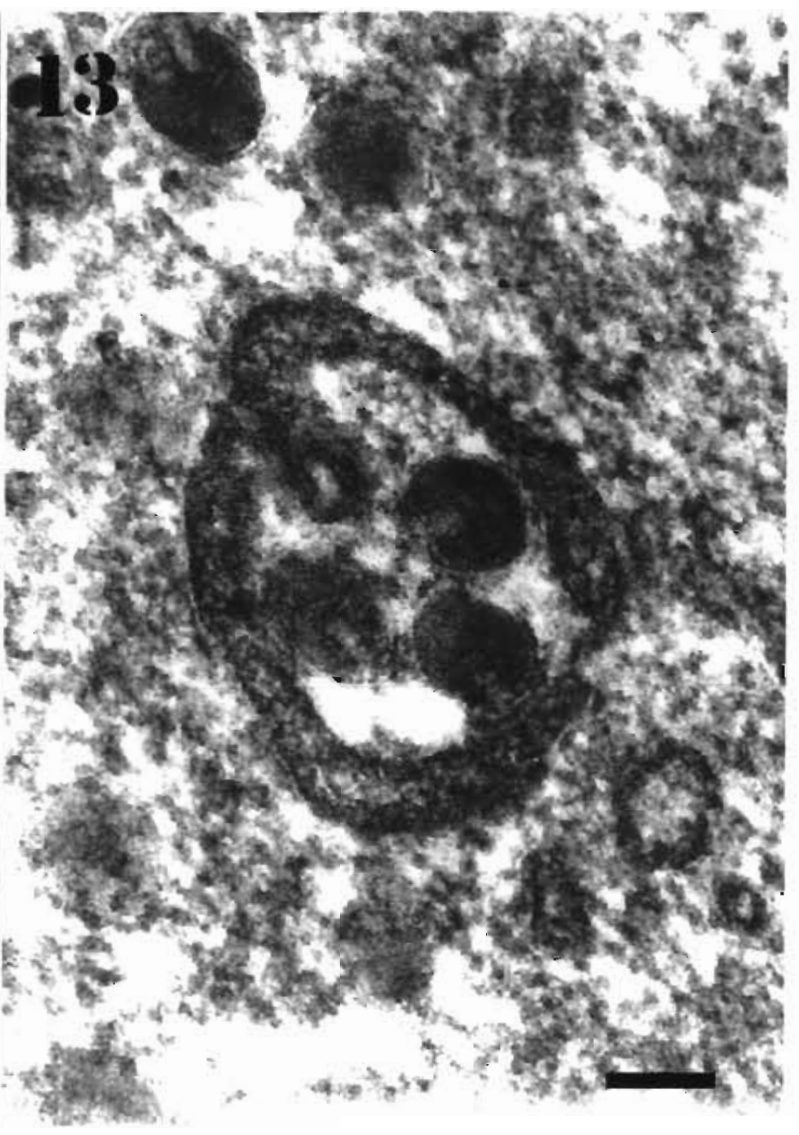

Figs. 12 to 14 . PKX extrasporogonic parasite. Fig. 12. Parasite plasmalemma appears indistinct with numerous EDBs. ( $\star$ ) Host cell. Scale bar $=200 \mathrm{~nm}$. Fig. 13. Cup-like multivesicular body enclosing 4 EDBs in extrasporogonic parasite. Scale bar $=100 \mathrm{~nm}$. Fig. 14. EDBs aligned to confronting cisternae. Scale bar $=100 \mathrm{~nm}$ 
ternae were $600 \mathrm{~nm}$ in length and $40 \mathrm{~nm}$ wide, with electron-dense material between them. EDBs were also occasionally noted to align to the delimiting vacuole surrounding the secondary cell; however interactions with this structure were not noted.

\section{DISCUSSION}

Much remains unknown about the biology of the PKX myxosporean and its interactions with the fish host. The inflammatory pathology associated with the infection coincides with the proliferation of the extrasporogonic stage of the parasite (Clifton-Hadley et al. 1987). The extrasporogonic stage appears to be able to evade destruction by the immune system until the release of secondary cells. To achieve this it has been postulated that the EDBs of the primary cell may have a role as a rescue mechanism for the extrasporogonic parasite against the fishes' immune system (MacConnell et al. 1989). The observation in this study that the extrasporogonic parasite is closely associated with the surrounding phagocytes, with areas of its surface interdigitating with the surrounding cells, indicates that the parasite is actively interacting with the hosts cellular immune response. Because of their association with the parasites cell surface and possible immunological interactions, it is desirable to increase our understanding of the function of the EDBs.

The results from this study demonstrate that there are 2 membranes associated with EDBs. There is the delimiting membrane that surrounds the matrix of the body and can extend into the lucent bar with an additional membrane that 'caps' this bar. The electron-lucent bar therefore represents a membrane-bound vesicle within an electron-dense shell. When viewed in sections not treated with Osmium tetroxide, some of the electronlucent bars appear as lucent ' $T$ 's. Osmium tetroxide is believed to stain tissues by the reduction of unsaturated lipids (Hayat 1993). This suggests that the core of these EDBs represented by the cross bar of the ' $T$ ' is rich in unsaturated lipids. Transverse sections across the electron-lucent bar further indicate 4 lobes of lipid-rich material that are associated with the base of the electronlucent bar. However, it has to be noted that the internal structure of the EDB can only be inferred from these results. EDBs that contained an electron-lucent cross that would be expected in certain cross-sections through the bodies were not observed during this study. In addition, these EDBs were noted alongside EDBs that only possessed an electron-lucent bar. This may be due to the orientation of the EDBs in the section or may be because the lucent ' $T$ 's represent a specific part of the EDBs developmental pathway, where they possess relatively large concentrations of unsaturated lipids
Smith et al. (1984) described the production of the EDBs in PKX both by the Golgi apparatus and by a vesicular entity. Although these 2 structures were apparently morphologically dissimilar, these authors did not rule out the possibility these structures were part of the same production system. Such vesicular entities were not encountered within this study although the genesis of EDBs was observed on the transGolgi face of the Golgi apparatus. The vesicular entity probably represents part of the trans-Golgi network (TGN) viewed face on, as it appears to be morphologically identical to such structures described in other cell types (Teichberg \& Holzmann 1973). The function of the TGN is believed to be for the production of membrane-delimited carrier structures that transport materials across the cell such as enzymes, secretory substances and material destined for the cell surface (Holzmann 1989). The presence of 'tail' forms of EDBs was also noted in this study as described by Ferguson $\&$ Needham (1978). Whether these 'tail' forms represent packaging of material into the EDB or plasticity in the membrane surrounding the EDB is unclear.

The presence of EDBs associated with the plasmalemma was always observed within the primary cell of the parasite. Interactions with the plasmalemma only appeared when the membrane of the bodies became aligned with or fused to it. This fusing of membranes was previously noted by Ferguson \& Needham (1978). However, exocytosis of the bodies' contents as described by Smith et al. (1984) was never observed in this study, suggesting that it is a relatively rare phenomenon. When the bodies fused with the plasmalemma in this study, their electron-dense contents were not ejected extracellularly; rather the bodies appeared to interact with the plasmalemma, adding, exchanging or removing a substance from it. Due to the density of the plasmalemma in areas where the bodies fuse, it has been suggested that it is the dense substance of the cell membrane that is being transported (Smith et al. 1984). The purpose of this material is unclear although it may be involved in evasion of the immune response or in the physical strengthening of the membrane. One of the functions of the Golgi apparatus is for the recycling of internal membranes to the cell surface for the renewal of the cell membrane (Fawcett 1994). Because some EDBs are rich in unsaturated lipids that are associated with the lucent bar, we suggest that it is a modified lipid that is transported to the plasmalemma. Although the dense matrix of the EDBs does not appear to be secreted extracellulary by the primary cell, the contents of the electron-lucent vesicle may be. Therefore, the bodies may have more than 1 function in relation to the surface of the cell, both that of lipid transport and transport of the contents of the lucent bar to be secreted. 
EDBs were seen to be actively engulfed by cup-like structures resembling MVBs as described by Holzmann (1986) in mammalian tissues. They were also observed in maturing MVBs, suggesting that they enter the lysosomal pathway to be degraded by the cell. However, whether this is attributed to crinophagy or autophagy or for the reduction of materials collected from the cell surface remains unknown. However, the occurrence of EDBs in, and their engulfment by, MVBs was a relatively unusual phenomena compared to their formation on the Golgi apparatus. Furthermore, their apparently selective engulfment by MVBs and their retention in disintegrating primary cells suggest that their association with the MVBs is due to crinophagy rather than autophagy. The role of the EDBs therefore appears to be that of secretion and the addition of material to the plasmalemma rather than for the collection of materials from the cell surface.

There are striking morphological and developmental similarities between the EDBs and the haplosporosomes found in members of the Haplosporidea. They are membrane-bound, electron-dense inclusions, often with an internal structure, that are made on the Golgi apparatus and that migrate and orient themselves towards the plasmalemma (Perkins 1971, Scro \& Ford 1990). The function of the haplosporosomes is unclear although it has been suggested that they are viral in origin (Perkins 1971, Hine \& Wesney 1992). They may participate in spore wall formation (Ginsburger-Vogel \& Desportes 1979) or they may act as an energy reserve in sporulation (Avezedo et al. 1985). Previous cytochemical work on haplosporosomes has demonstrated that they are composed of a protein matrix with periodate-reactive complex carbohydrates and that they possess an external membrane of glycoprotein and an internal membrane containing lipid (Azevedo et al. 1985). The EDBs noted in this study also contain an external membrane containing glycoconjugates, and some at least are rich in internal lipid. However, the matrixes of PKX EDBs have been reported as Thiéry negative, indicating that they do not contain carbohydrates (Lom et al. 1989). This appears to be an important feature of the haplosporosomes of the Haplosporidea, allowing them to be distinguished from the sporoplasmasomes contained in species of Myxosporea (Lom et al. 1989). The EDBs of PKX are morphologically distinct from sporoplasmasomes, suggesting that they possess a different function from these bodies. However, the sporoplasmasomes of the myxosporean Tetracapsula bryozoides bear a close morphological resemblance to the EDBs of PKX (Feist 1997). Comparisons of PKX 18S rDNA with a range of bryozoan-infecting myxosporeans has demonstrated that PKX has close affinities with these parasites and may indeed use Bryozoa species as a host. This may explain the morphological similarities of PKX EDBs with the sporoplasmasomes of $T$. bryozoides (Anderson et al. 1999). Although they may be biochemically different, the haplosporosomes found in members of the Haplosporidea and the sporoplasmasomes of $T$. bryozoides both appear late in sporogenesis and are associated with the development of the spore wall. Therefore, it is suggested that they have functions similar to those of the EDBs of PKX, that is, to transport materials destined for the surface of the parasite whether for the plasma membrane or the spore wall.

Acknowledgements. The authors would like to thank Marguerite Kobs and Linton Brown for their technical assistance with electron microscopy. The authors would also like to thank the Natural Environment Research Council, Swindon, UK, for funding this research.

\section{LITERATURE CITED}

Anderson CL, Canning EU, Okamura B (1999) 18S rDNA sequences indicate that PKX organism parasitizes bryozoa. Bull Eur Assoc Fish Pathol 19:94-97

Azevedo C, Corral L (1985) Cytochemical analysis of the haplosporosomes and vesicle-like droplets of Haplosporidium lusitanicum (Haplosporida, Haplosporididae), parasite of Helcion pellucidus (Prosobranchia). J Invertebr Pathol 46: 281-288

Canning EU, Okamura B, Curry A (1996) Development of a myxosporean parasite Tetracapsula bryozoides gen. n. et sp. n. in Cristatella mucedo (Bryozoa: Phylactolaemata). Folia Parasitol 43:249-261

Clifton-Hadley RS, Bucke D, Richards RH (1987) A study of the sequential clinical and pathological changes during proliferative kidney disease in rainbow trout, Salmo gairdneri Richardson. I Fish Dis 10:335-352

Fawcett DW (1994) A textbook of histology, 12th edn. Chapman and Hall, London

Feist SW (1997) Pathogenicity of renal myxosporeans of fish. Bull Eur Assoc Fish Pathol 17:209-214

Feist SW, Bucke D (1987) Ultrastructural aspects of PKX, the causative agent of proliferative kidney disease in rainbow trout, Salmo gairdneri Richardson. J Fish Dis 10:323-327

Ferguson HW, Needham EA (1978) Proliferative kidney disease in rainbow trout Salmo gairdneri Richardson. J Fish Dis 1:91-108

Ginsburger-Vogel T, Desportes I (1979) Etude ultrastructurale de la sporulation de Paramarteilia orchestiae gen. n., sp. n., parasite de l'Amphipode Orchestia gammarellus (Pallas) J Protozool 26:390-403

Hayat MA (1993) Stains and cytochemical methods. Plenum Press, New York

Hedrick RP, MacConnell E, de Kinkelin P (1993) Proliferative kidney disease of salmonid fish. Annu Rev Fish Dis 3: $277-290$

Hine PM, Wesney B (1992) Interrelationships of cytoplasmic structures in Bonamia sp. (Haplosporidia) infecting oysters Tiostrea chilensis: an interpretation. Dis Aquat Org 14 $59-68$

Holzmann E (1989) Lysosomes. Plenum Publishing Corporation, New York

Kent ML, Hedrick RP (1986) Development of the PKX myxo- 
sporean in rainbow trout Salmo gairdneri. Dis Aquat Org 1:169-182

Kent ML, Khattra J, Hervio DML, Devlin RH (1998) Ribosoma DNA sequence analysis of isolates of the PKX myxosporean and their relationship to the genus Sphaerospora J Aquat Anim Health 10:12-21

Lom J, Molnár K, Dyková I (1986) Hoferellus gilsoni (Debaisieux, 1925) comb. n. (Myxozoa, Myxosporea): redescription and mode of attachment to the epithelium of the urinary bladder of its host, the European eel. Protistologica 22:405-413

Lom J, Feist SW, Dyková I, Kepr T (1989) Brain myxoboliasis of bullhead, Cottus gobio L., due to Myxobolus jirovecisp. nov.: light and electron microscope observations. J Fish Dis $12: 15-27$

MacConnell E, Smith CE, Hedrick RP, Speer CA (1989) Cellular inflammatory response of rainbow trout to the protozoan parasite that causes proliferative kidney disease. J Aquat Anim Health 1:108-118

Morris DJ, Adams A, Richards RH (1997) Studies on the PKX myxosporean using immunogold electron microscopy and immunohistochemistry. J Aquat Anim Health 9:165-273

Perkins FO (1971) Sporulation in the trematode hyperparasite Urosporidium crecens de Turk 1940 (Haplosporia: Haplo-

Editorial responsibility: Wolfgang Körting,

Hannover, Germany sporididae) an electron microscope study. J Parasitol 57 : $1: 9-23$

Saulnier D, Phillippe H, de Kinkelin P (1999) Molecular evidence that the proliferative kidney disease organism unknown (PKX) is a myxosporean. Dis Aquat Org 36:209-212

Scro RA, Ford SE (1990) An electron microscope study of disease progression in the oyster Crassostrea virginica infected with the protozoan parasite Haplosporidium nelsoni (MSX). In: Perkins FO, Cheng TC (eds) Pathology in marine science. Academic Press, San Diego, p 229-254

Seagrave CP, Bucke D, Alderman DJ (1980) Ultrastructure of a Haplosporean-like organism: the possible causative agent of proliferative kidney disease in rainbow trout. J Fish Biol 16:453-459

Smith CE, Morrison JK, Ramsey HW, Ferguson HW (1984) Proliferative kidney disease: first reported outbreak in North America. J Fish Dis 7:207-216

Teichberg S, Holzmann E (1973) Axonal agranular reticulum and synaptic vesicles in cultured embryonic chick sympathetic neurons. J Cell Biol 57:88-105

Voronin VN, Chernysheva NB (1993) An intracellular gill parasite as the possible causative agent of mortality during swim-bladder inflammation in common carp, Cyprinus carpio L. J Fish Dis 16:609-611

Submitted: August 28, 1999; Accepted: November 18, 1999 Proofs received from author(s): January 14, 2000 